\title{
Translating science into policy: mental health challenges during the COVID-19 pandemic
}

\author{
Jair J. Mari, ${ }^{1}$ iD Ary Gadelha, ${ }^{1}$ (iD Christian Kieling, ${ }^{2,3}$ (iD Cleusa P. Ferri, ${ }^{1}$ (iD Flavio Kapczinski, ${ }^{4,5}$ (iD \\ Antonio E. Nardi, ${ }^{6,7,8}$ (iD Naomar Almeida-Filho, ${ }^{9,10}$ (iD Zila M. Sanchez, ${ }^{11}$ iD Giovanni A. Salum ${ }^{12}$ (iD \\ ${ }^{1}$ Departamento de Psiquiatria e Psicologia Médica, Escola Paulista de Medicina, Universidade Federal de São Paulo (UNIFESP), São Paulo, \\ $S P$, Brazil. ${ }^{2}$ Serviço de Psiquiatria da Infância e Adolescência, Hospital de Clínicas de Porto Alegre (HCPA), Universidade Federal do Rio \\ Grande do Sul (UFRGS), Porto Alegre, RS, Brazil. ${ }^{3}$ Departamento de Psiquiatria e Medicina Legal, UFRGS, Porto Alegre, RS, Brazil. \\ ${ }^{4}$ Departamento de Psiquiatria, UFRGS, Porto Alegre, RS, Brazil. ${ }^{5}$ McMaster University, Hamilton, Canada. ${ }^{6}$ Instituto de Psiquiatria, Faculdade \\ de Medicina, Universidade Federal do Rio de Janeiro, Rio de Janeiro, RJ, Brazil. ${ }^{7}$ Academia Nacional de Medicina, Rio de Janeiro, RJ, Brazil. \\ ${ }^{8}$ Academia Brasileira de Ciências, Rio de Janeiro, RJ, Brazil. ${ }^{9}$ Instituto de Estudos Avançados, Universidade de São Paulo, São Paulo, SP, \\ Brazil. ${ }^{10}$ Instituto de Saúde Coletiva, Universidade Federal da Bahia, Salvador, BA, Brazil. ${ }^{11}$ Departamento de Medicina Preventiva, Escola \\ Paulista de Medicina, UNIFESP, São Paulo, SP, Brazil. ${ }^{12}$ Seção de Afeto Negativo e Processos Sociais, Departamento de Psiquiatria e \\ Medicina Legal, HCPA, UFRGS, Porto Alegre, RS, Brazil.
}

\begin{abstract}
Several stressors associated with the coronavirus disease 2019 (COVID-19) are expected to affect the mental health of global populations: the effects of physical distancing, quarantine, and social isolation; the emotional suffering of health and other frontline workers; neuropsychiatric sequelae in those affected by the virus; the impact to families of lives lost to the disease; differential effects for those with severe mental disorders; and the consequences of social and economic deterioration.

In this context, we sought: to form a panel of Brazilian experts on child and adolescent health, neurodevelopment, health services, and adult and elderly mental health; and to compile evidencebased interventions to support suggested policy changes in Brazil to mitigate the expected increase in mental health disorders during the pandemic and its mental health consequences. The following actions are recommended: 1 ) invest in prevention programs for the safe return of students to schools; 2) adopt evidence-based psychosocial interventions to maintain an adequate environment for child and adolescent development; 3) target socially vulnerable populations and those experiencing discrimination; 4) train primary care teams to solve common mental health problems, provide needsbased assessments, and manage long-term, at-home care for older patients; 5) invest in technological advancements (e.g., telemedicine, e-Health, and web-based algorithms) to promote coordinated care; 6) increase access to and literacy in the use of computers and mobile phones, especially among older adults; 7) expand protocols for remote, brief psychotherapy interventions and psychoeducation to manage common mental health problems.
\end{abstract}

Keywords: Mental health; coronavirus infection; brief psychotherapy; telehealth

\section{Introduction}

Coronavirus disease 2019 (COVID-19), caused by severe acute respiratory syndrome coronavirus 2 (SARS-CoV-2), has affected millions of people worldwide, imposed major burdens on all health systems, and become an unprecedented challenge to a whole generation. Brazil is a continental country with an estimated population of more than 200 million, diverse geographic regional realities, and alarming social inequality. The disease dissemination path illustrates Brazil's diversity: it first struck urban areas and then spread to more rural areas, ultimately reaching even isolated indigenous populations. Inequality is also reflected by the effects of the pandemic; differences in

Correspondence: Jair J. Mari, Universidade Federal de São Paulo, Escola Paulista de Medicina, Departamento de Psiquiatria, Rua Major Maragliano, 241, Vila Mariana, CEP 04017-030, São Paulo, SP, Brazil.

E-mail: jamari17@gmail.com

Submitted Oct 18 2020, accepted Dec 02 2020, Epub Feb 122021. contamination rates and mortality suggest distinct disease patterns. $^{1}$ The initial measures aimed at controlling disease spread and establishing infrastructure to deal with more severe clinical cases. However, the perspective of mental health suffering and psychiatric morbidity caused by pandemic, and compounded by the effects of quarantine, social isolation, and economic crisis, has received comparatively little attention.

In the case of these intriguing biological organisms designated "human beings" the symbolic order must necessarily be included. So, the series (organismgroup-population-environment) can be read as (subjectfamily-society-culture). The first order can be termed the "biodemographic" hierarchy, and the second, the

How to cite this article: Mari JJ, Gadelha A, Kieling C, Ferri $\mathrm{CP}$, Kapczinski $\mathrm{F}$, Nardi AE, et al. Translating science into policy: mental health challenges during the COVID-19 pandemic. Braz $\mathrm{J}$ Psychiatry. 2021;43:638-649. http://dx.doi.org/10.1590/1516-44462020-1577 
"sociocultural" hierarchy. ${ }^{2,3}$ Mental disorders, for example, are a consequence of biological and socioculturalenvironmental interactions, and the pandemic created an imbalance between risk and protective factors, exacerbating many existing risk factors and generating additional ones. Despite the challenges posed by this new, unprecedented reality, ${ }^{4}$ it could be catalytic in improving the way health systems and society are organized to protect and promote vulnerable populations' mental health. Population health science focuses on pervasive, ubiquitous factors and how their distribution shapes individual health within and across populations. The case for applying this approach to the field of mental health has been made with the rationale that even small changes in upstream, macrosocial factors can substantially impact the health of populations. Thus, every scenario requires specific solutions, while balancing best-evidence practices and available resources.

COVID-19 should therefore be viewed and addressed from a syndemic approach, acknowledging the importance of biological and social interactions for prognosis, treatment, and health policy. ${ }^{5}$ For instance, available evidence has already identified a threefold increase in psychological distress, loneliness, and depression symptoms in the United States. ${ }^{6,7}$ Considering the syndemic effect of social determinants on heath, a recent online survey was conducted with a convenience snowball sample of essential workers from Brazil and Spain $(n=3,745)$, and found a high prevalence of depression and anxiety (27.4\%), largely and closely associated with social inequalities. ${ }^{8}$ Social isolation due to quarantining and self-isolation has been devastating for everyone, but especially for the vulnerable, such as those with severe mental disorders, ${ }^{9}$ who experience additional anxiety and distress in response to changes caused by the pandemic. Even food security was a major problem, as many patients had no means to eating properly during the pandemic. $^{10}$

Children and adolescents are the least affected group in terms of direct clinical outcomes resulting from the COVID-19 pandemic, but paradoxically, they likely constitute the most vulnerable group regarding potential psychological consequences of pandemic-related family/ societal disruptions. ${ }^{11}$ Physical distancing, school closures, economic losses, and the unemployment of parents/ caregivers have negatively impacted the social, educational, and emotional support systems that children and adolescents typically rely on, even during emergencies. ${ }^{12}$

Within this multifaceted scenario, how will Brazil, one of the countries most affected by COVID-19 and struggling with health care deficits even before the pandemic, cope with such a challenge? All these pressing needs are a call for the adoption of new technologies and more rational use of resources. The Brazilian Unified Health System (Sistema Único de Saúde, SUS) is unprepared to handle the oncoming mental health crisis, but the population has never needed mental health care as much as it does now. Thus, we aim to present recommendations to policymakers regarding the future of mental health by taking Brazil as an example of the challenges that have emerged during the pandemic, by making the best use of available human resources, innovative technologies, and the reorganization of mental health services.

\section{Children and adolescents}

Preliminary evidence suggests that those children and adolescents with disorders relating to anxiety, stress, and/ or mood experience symptom intensification because of fear of the coronavirus. Meanwhile, because of disruptions in routine and household structure, those with neurodevelopmental disorders (e.g., autism and attention-deficit/hyperactivity disorder) experience exacerbation of behavioral symptoms. ${ }^{13}$ Children with special educational needs and disabilities also constitute a vulnerable group that requires additional support. ${ }^{14}$

The absence of a pre-existing mental disorder, however, does not imply protection regarding mental health problems during or after the COVID-19 crisis. While the educational and socioemotional impacts of prolonged absence from school are yet to be determined, the increased time children and adolescents are spending at home may increase their risk of experiencing maltreatment, especially in developing countries where economic and social inequality is rampant. Therefore, ensuring that children are busy and safe at home can be daunting to crowded households in low-income areas, ${ }^{15}$ such as Brazil's metropolitan peripheries.

Multiple approaches are required to protect children and adolescents' mental health during and after the pandemic. Considering the limited access to health care systems before the pandemic, Brazil and other low- and middle-income countries (LMIC) must prioritize the most vulnerable individuals and families. For example, healthcare professionals should actively identify pandemicrelated symptom exacerbation. Also, since many families may be afraid to take their children to healthcare facilities, providing evidence-based education about the pandemic is crucial. In LMICs, many families have been substantially impacted by the economic consequences of the COVID-19 crisis. While temporary cash-transfer programs were of tremendous value when readily applied, more action is still needed. Protecting the mental health of the most vulnerable demands coordinated action from the government to provide multiple stakeholders (e.g., youths, parents, school staff, healthcare professionals) with trusted information and support.

New research, including analyses of existing/ongoing studies, will play a pivotal role in guiding policies to address the impact of the pandemic. Despite its challenges and social consequences, young people have reported a sense of regaining control through community and civic engagement. ${ }^{16}$ This aligns with the idea that adolescents recognize their participation in healthcare policy design and implementation as an important issue, and should be a focus for investment. ${ }^{17}$ Young people's agency could significantly impact the coproduction of research and peer-led interventions. It has been suggested that actively involving youth in conceptual stages of research design and in interventions where they can support each other is more likely to produce sustainable results during the COVID-19 crisis and beyond. ${ }^{16}$ 


\section{Adolescents, back to school: how to prevent bullying and alcohol/drug use after a pandemic}

Before the pandemic, the National School Health Survey (Pesquisa Nacional de Saúde do Escolar) showed that $55.5 \%$ of 9th-graders in Brazil had already consumed alcoholic beverages, $21.4 \%$ had experienced at least one episode of drunkenness, $18.4 \%$ has used tobacco, and $9 \%$ had used illicit drugs. ${ }^{18}$ The same survey found that $19.8 \%$ of students reported involvement in bullying, ${ }^{19}$ which is consistently associated with depression, anxiety, social phobia, suicidal ideation, and drug misuse ${ }^{20}$ Early interventions are needed to simultaneously address school violence, mental health, and drug use. ${ }^{21}$ Already a need during times of social stability, bullying prevention gains additional importance in a pandemic scenario, as children and adolescents are suffering the psychological burden of quarantine and could potentially develop acute stress disorder, adjustment disorder, post-traumatic stress disorder, irritability, and/or anxiety. ${ }^{22}$

In years to come, adolescents will probably face a greater challenge in terms of mental disorders, drug use, and violence in the form of bullying, as these are likely to increase upon returning to school. It is essential that the education system should adopt adequate prevention programs that have shown potential to effect significant reductions in drug use and school violence. ${ }^{21,23,24}$ However, a substantial number of these were either never evaluated for effectiveness, ${ }^{25}$ showed neutral/flat results, ${ }^{24}$ or had a potential iatrogenic effect (i.e., led to an increased occurrence of the behavior they sought to prevent). ${ }^{26,27}$

The Brazilian Ministry of Health and United Nations Office on Drugs and Crime contributed to the Integrated Plan to Combat Crack and Other Drugs (Plano Integrado de Enfrentamento ao Crack e Outras Drogas; Decree 7.637 of December 8, 2011), which mandates implementation of drug/violence prevention programs in public schools and the welfare system. Accordingly, they chose three evidence-based programs that had consistently shown positive results in other countries and conducted their cross-cultural adaptation and implementation ${ }^{28}$ : Unplugged for adolescents aged 10 to 14 in middle schools ${ }^{29}$; the Good Behavior Game (GBG) for children between 6 and 10 attending primary school ${ }^{30}$; and the Strengthening Families Program (SFP), which focused on families in the public welfare system. ${ }^{31}$

These programs underwent several evaluations with different study designs, allowing their adaptation into a current version. Among them, Unplugged (now referred to as \#Tamojunto2.0) was the only one subjected to a complete evaluation cycle (i.e., the feedback loop of adaptation-evaluation-readaptation-reevaluation), having undergone three cycles of cultural adaptation and evaluation since 2013. Unplugged is a competency curriculum based on a complex model that integrates theories such as social norms, social learning, problem behavior, and reasoned action. ${ }^{32}$ The curriculum, which was previously implemented by teachers, aims to develop general social skills to reduce the effects of social influence as well as alcohol and drug use. ${ }^{33}$ In Brazil, its effects on alcohol and inhalant use were mixed, ${ }^{34,35}$ but bullying was reduced. ${ }^{36}$

Focused on primary-school students, the Ministry of Health Elos program is the Brazilian implementation of GBG, is one of the most evaluated prevention programs worldwide, providing a contingency program for classroom management that is understood and disseminated as a behavioral vaccine. ${ }^{37}$ The GBG's immediate effects are the reduction of aggression and disruptive behavior in different populations. ${ }^{38}$ Teachers implement Elos in the classroom by dividing students into teams that must comply with the teacher's rules, where students receive points for appropriate classroom behavior. The GBG generates peer interaction and support, ${ }^{39}$ which will be even more essential upon reopening schools in a postpandemic scenario. In the long run, the program affects various behaviors, emphasizing reduced drug use and decreased engagement in high-risk sexual behaviors in adulthood. ${ }^{30}$

Finally, Familias Fortes is a program aimed at the welfare system and based on the famous SFP, one of the most important evidence-based family programs for drug use prevention, which shows long-term results of adolescent drug use reduction. ${ }^{40}$ The program is based on several theories, offering parental skills (e.g., communication, family cohesion, parental supervision, and parental emotional support) and life skills (e.g., assertive social skills for coping with peer pressure, emotional regulation skills, and life projects) for adolescents. ${ }^{41}$

An evaluation of these programs in Brazil shows their high acceptability and viability, allowing the data-driven improvement of content and dissemination techniques. ${ }^{42-45}$ On the other hand, several strategies must be considered for the programs to be effectively incorporated as a public policy in the post-pandemic period. For example, partnering with the Ministry of Education, school programs need Elos and \#Tamojunto2.0 to be incorporated into the curriculum as political-pedagogical projects through the Health at School Program (Programa Saúde na Escola), so they can become a regular primary care activity within communities. Moreover, to ensure sustainability, programs need formal implementation and sustainable monitoring strategies to keep them from lapsing with changes in government. In a post-pandemic scenario, the health authorities should support programs of this kind to reduce students' risk behaviors.

\section{Severe mental illness}

Schizophrenia can be regarded as a prototype for severe mental illness. So, most concerns described in this section and correlated recommendations apply to other cases of severe mental disorders as well. Schizophrenia affects 0.2 to $0.4 \%$ of the general population ${ }^{46}$ and results in the highest direct cost to health systems across Western countries. In recent decades, community treatment became possible, which allowed for improved social and functional outcomes, but recovery rates remain low. ${ }^{47}$ The general population's mortality gap widened due to clinical comorbidities, ${ }^{48}$ while the individual and family burden remains massive. ${ }^{49}$ 
In Brazil, the public health system is responsible for providing care for the entire population. The mental health system starts at the primary level and consists of different levels of care, with community treatment organized around its core facility, the Community Psychosocial Centers (Centros de Atenção Psicossocial, CAPS). Despite advances, the care provided remains limited, which is strikingly evident in Brazil's official guidelines for schizophrenia treatment. ${ }^{50}$ Meanwhile, no policies are tackling any of these challenges, and available bestevidence recommendations have been disregarded.

The pandemic has instigated three new concerns regarding schizophrenia: 1) morbidity and mortality due to COVID-19; 2) a higher incidence of psychotic relapses in patients with a previous diagnosis; and 3) rising incidences of psychotic disorders. Patients with schizophrenia are potentially even more vulnerable to infection and have a higher risk of developing more severe forms of COVID-19. ${ }^{51}$ Evidence suggests the risk of a future increase in incidence involving immune-mediated mechanisms, ${ }^{52}$ whereas case reports underscore a relapse risk. ${ }^{53}$ Controversially, although preventative care should have been provided, the pandemic led most primary and secondary mental health facilities to either close or restrict appointments temporarily. Moreover, some psychiatric hospitals, such as the 200-bed Hospital Galba Veloso, in the state of Minas Gerais, were redesignated as COVID19 treatment centers, and the government may not return these beds to psychiatric care after the pandemic, deepening the ongoing scarcity of acute psychiatric beds in the country. Thus, changes in the way schizophrenia is treated in LMIC countries and Brazil in particular are imperative due to the pandemic.

The typical proposal for modifying the disease trajectory targets patients at their first episode of psychosis; indeed, specialized care to first-episode patients is demonstrably cost-effective across different countries, improving outcomes with regard to relapses, employment, suicide attempts, and quality of life. ${ }^{54-56}$ However, implementation of early-intervention services is highly heterogeneous worldwide and faces even more barriers in LMICs due to scarce resources, weak infrastructure, the absence of mental health policies, a lack of healthcare workers, and stigma. ${ }^{57}$ In Brazil, only three early-intervention services were identified in a recent scoping review, all linked to university psychiatry services in large urban areas. Fostering early-intervention services was likely unfeasible even before the pandemic, but now, the imminent economic crisis will worsen the situation.

During this crisis, although mental health professionals must learn to work faster with fewer resources, a new way of communicating has emerged for giving and receiving support. This mode can access people who are difficult to reach with existing, conventional protocols. ${ }^{9} \mathrm{~A}$ comprehensive and integrated proposal must be drafted that aligns the best available evidence while optimizing economic and human resources and delivering innovation via new technologies. ${ }^{58}$ Below are some gaps that could be tackled:

1) Organize and publicize specific policies and educational materials to suit the needs of patients with schizophrenia and other severe mental disorders;
2) Define new outcomes for quality of care that encompass general health and recovery-oriented measures;

3) Implement intensive care management teams and outline stepped care to optimize resources in LMICs. Reducing consultation time restricts psychiatrists' effectiveness, while primary, non-specialized care and screening can improve efficiency, especially when community agents actively probe for untreated patients in the early stages of severe mental illness;

4) Incorporate mental health literacy to school curricula to foster self-care, reduce stigma, and allow early treatment; develop closer collaboration between education and health systems;

5) Ensure that all educational material/guidelines are available to mental health and primary care professionals through websites (e.g., the Ministry of Health) and mobile apps;

6) Ensure that each first-episode patient is identified and receives coordinated, multidisciplinary care at disease onset;

7) Implement routine training and supervision for professionals when they begin a service and continue this practice;

8) Organize specialized centers in the largest metropolitan areas (population $>1$ million) for patients experiencing their first episode of psychosis. Directly attend to or discuss patients upon request of the CAPS team and provide telehealth assistance to those in smaller surrounding cities;

9) Utilize mobile apps to help patients/families remember medication times, search for answers to questions, keep a symptom journal, or contact their mental health team;

10) Ensure that all these suggestions involve patients and their families from the outset and throughout implementation.

Although none of the abovementioned proposals differs from pre-pandemic needs, COVID-19 underscores the current demand for a system-level change in mental health policies.

\section{Older adults' mental health}

Population aging is happening much faster in LMICs than in high-income countries. In Brazil, while the total population increased 21.6\% between 1997 and 2017, there was an increase of $49.2 \%$ in those aged 60 and above, and $65 \%$ in those 80 and above. Currently, nearly 30 million Brazilians are aged 60 or older. ${ }^{59}$ These individuals are at higher risk of physical and mental health problems, mount weaker responses to infections, are more likely to have multiple chronic conditions, and are more susceptible to social isolation, which has been shown to be a strong predictor of both increased mortality ${ }^{60}$ and mental disorders. ${ }^{61}$ According to the World Health Organization (WHO), ${ }^{62}$ approximately $20 \%$ of adults aged 60 and older have a mental/neurological disorder, and these disorders account for $17.4 \%$ of years lived with disability (YLDs) among older people. Dementia and depression are the most common such conditions, and a quarter of all suicides occur among older people, ${ }^{62}$ 
despite only representing between $10-15 \%$ of the population. In Brazil, the prevalence of depression is around $20 \%$ among those aged 60 and over, ${ }^{63}$ and suicide rates are $60 \%$ higher among those aged 70 and above compared to nationwide rates. ${ }^{64}$ This is likely to be aggravated by the current pandemic, with long-term effects in the older population. In the state of Sao Paulo, of 697,530 confirmed COVID-19 cases as of August 16, $2020,117,530(16.8 \%)$ were in those aged 60 and over. Meanwhile, the case fatality rate in those under age 60 was $1.1 \%$, while in those over it was $17.2 \% .{ }^{65}$ A recent study showed a similar proportion of death among 42,216 older adults living in 1,802 long-term care institutions in Brazil; $6.1 \%$ of individuals were infected, with a $17.6 \%$ fatality rate. $^{66}$ To control mortality, most guidelines recommend reinforcing quarantine measures for older people. These measures, however, can evoke fear and apprehension in the elderly, who are already more vulnerable, placing them at risk of worsening pre-existing chronic conditions and developing/worsening social isolation and related mental health issues.

Social isolation and loneliness are themselves linked to higher mortality, ${ }^{60,67}$ depression, and a reduced sense of well-being among older people. ${ }^{68}$ Combined with worries about whether they will receive the necessary care during the pandemic, older adults may feel that they are deemed as a lower priority, less worthy of care, and a burden to society, which may increase their suicide risk. ${ }^{69}$ Physical distancing and social isolation also increase sedentariness, which has been related to worsening of physical and mental function, especially among older people who have had to discontinue their habitual physical activities. ${ }^{70}$ Furthermore, social isolation can exacerbate age-related conditions associated with cognitive decline, such as dementia. Approximately two million Brazilians are living with dementia. ${ }^{71}$ Psychotic symptoms, wandering, agitation, and aggression are all features of later stages of dementia which are causing significant stress to those with the condition and their families and caregivers. These symptoms make it difficult to follow recommendations relating to hygiene and social distancing. Lastly, older people in isolation may also be at higher risk of abuse and increased alcohol consumption. Although, in a recent survey, telephone contact with 90 older adults during the pandemic showed that most had either reduced or stopped drinking, some postulate that this decrease may be seen in the short term, while distress from the current pandemic may eventually lead to increased consumption. ${ }^{72}$

We still know little about the short- and long-term consequences of the pandemic for the mental health of older people. In the long-term, post-pandemic era, we must consider health care strategies for older people that are concerned with easily accessible care (especially community and primary care services), with special attention being paid to the psychological, cognitive, functional, behavioral, physical, and social problems that are usually related to aging. Health professionals must be trained to recognize mental disorders (especially in older populations, due to their multimorbidity) via a basic curriculum that entails diagnostics, basic needs assessments, long-term support, outreach care, and the management of older patients in their homes. It is important to increase access to and literacy in the use of computers and mobile phones, with the support of peers and family. This can increase access to interventions that can promote physical activity and socialization. It is also important to promote the creation of a support network to encourage peer support to combat loneliness as well as increase awareness about older people's rights, which are currently addressed by a federal law in Brazil (Estatuto do Idoso).

\section{Economic and social inequalities}

Worldwide, the pandemic's impact tends to be more severe among socially deprived and politically oppressed populations. ${ }^{73}$ In different contexts, social determinants and health inequities produce a disproportionate burden of COVID-19-related morbidity and mortality. In contexts of extreme economic and social inequalities, as in the United States, the pandemic has enhanced prevailing inequities that are concentrated among racial and ethnic minorities, ${ }^{74}$ including those living in precarious housing conditions without access to water and sanitation but with high demographic density. This group is more affected by chronic diseases, deficiencies, and disabilities than the middle and upper classes. ${ }^{75}$

The pandemic has been socially determined on a global scale, striking particularly the deprived, vulnerable, and marginal sectors of society. ${ }^{76}$ The proportion of unemployed or those in informal work situations has increased, severely impacting personal behavior during the epidemic, given the difficulties that these groups face when it comes to adhering to quarantine and mitigating the effects of COVID-19. Physical distancing and other quarantine measures are virtually impossible to comply with by the poor, unemployed, self-employed, and others. ${ }^{77}$ The pandemic produced an economic crisis that is expected to significantly impact Brazil's social security and labor situation. Some face tremendous difficulty staying home for weeks because they lack the income to purchase necessities. Since they already face challenges accessing health, social assistance, and education services, it is vital to ensure an emergency minimum income that can ensure the survival of those in need during the pandemic. ${ }^{78}$

The first confirmed cases of COVID-19 in Brazil occurred among middle- and upper-class travelers returning from overseas trips via the entry points of the cities of São Paulo, Rio de Janeiro, and Fortaleza, who subsequently contaminated domestic and service workers, which, in turn, affected their poor peripheral communities. ${ }^{79}$ Then, the pandemic quickly expanded inland, striking small towns, rural settlements, indigenous peoples, quilombolas, and riverside populations, revealing the deep inequality of Brazilian social structure. Despite a failure to document the race/ethnicity in health service registries, inequality was reflected in excess deaths among poor, black, and indigenous populations, as compared to the rich, white, and urban dwellers. Fatality rates among these socially vulnerable groups tend to be 
higher because of the differential availability of public versus private health services. ${ }^{79}$

\section{Innovation, technology, and the mental health system}

The Brazilian Mental Health Policy was based on the 1990 Caracas Declaration, ${ }^{80}$ which focuses on safeguarding the civil rights of people with mental health conditions, decentralizing psychiatric care from psychiatric hospitals to community services, and replacing psychiatric beds with inpatient services in general hospitals. In Brazil, some of these principles were transformed into law in $2001^{81}$ and regulated in $2002^{82}$ by creating the CAPS, the cornerstone of the new mental health policy. Nine years later, the Ministry of Health published regulations that organized the Network of Psychosocial Care (Rede de Atenção Psicossocial, RAPs), ${ }^{83}$ describing the services composed within and providing guidelines for municipalities to implement a coordinated care system, including primary care, specialized mental health care, crisis management services, housing services, inpatient units, deinstitutionalization initiatives, and psychosocial rehabilitation programs. The composition of RAPs was revised in 2017 to include new service types (e.g., outpatient specialized services and new modalities of CAPS) and specialized/psychiatric hospitals, as well as to expand admission criteria for housing programs. ${ }^{84}$ The role of innovation and technology in supporting Brazil's RAPs has not been sufficiently explored in the literature and it might be central to the new organization of the mental health system during the pandemic, specifically to improve the availability of evidence-based treatments in primary care settings, to promote coordination and continuity of care among the distinct nodes of the Brazilian RAPs.

\section{Evidence-based primary care}

One of the important challenges for Brazilian RAPs is the low availability of evidence-based practices to treat common mental health conditions, such as stress related to life events, anxiety, depression, attention-deficit/hyperactivity disorder, and alcohol problems. ${ }^{85}$ Data from the 2013 National Health Survey (Pesquisa Nacional de Saude, PNS) revealed that the overall prevalence of depression in Brazil was approximately $7.9 \%$; among persons with depression, $78.8 \%$ did not receive any treatment, while $14.1 \%$ only received pharmacotherapy. ${ }^{85}$ These data suggest a large treatment gap for common mental disorders in Brazil, especially depression. ${ }^{86,87}$

The literature illustrates how technological advances can improve therapeutic options in primary care settings. Menezes et al. ${ }^{88}$ report pilot data on the use of mobile health technology - specifically, a low-intensity, psychoeducational, 6-week intervention delivered via mobile phones with nurse assistance to reduce depressive symptoms among individuals with diabetes or hypertension. Approximately $60 \%$ of patients improved after receiving the intervention, and acceptance rates were high, suggesting the feasibility of these strategies to reduce depressive symptoms. In another example, the TelePSI project $^{89}$ in Brazil consisted of remotely applied, brief (one- and four-session) protocols of cognitive behavioral therapy, interpersonal therapy, and psychoeducation to prevent and treat anxiety, depression, and irritability during the pandemic. From May to August 2020, more than 900 health professionals and essential-service workers participated, reporting high levels of satisfaction and symptomatic improvement. Adoption of the strategies illustrated by these two examples may improve access to evidencebased psychotherapy at a countrywide level and decrease the treatment gap for common mental health problems.

\section{Care coordination}

Care coordination is the deliberate organization of patient care activities between two or more participants involved in a patient's care to facilitate the appropriate delivery of health care services, ${ }^{90}$ and it is the first step for a health services network to function properly. The role of each node that composes the network must be defined so that, once it fulfills its goals, criteria are in place for transitioning to another node. Currently, no national guidelines exist for accepting people into mental health services or referring them to other services, which prevents services from specializing and attending to patients with specific mental health needs. Figure 1 depicts an example of the overall organization between distinct levels of mental health care.

One example of care coordination innovation, used in the city of Porto Alegre, state of Rio Grande do Sul, was the "matrix of mental health conditions and services." In the matrix, each health condition is depicted as a row and each service type as a column. ${ }^{91}$ For each mental health condition, clear criteria for referrals to lower- or upperlevel services should be reflected in primary care, specialized care, intensive care, and emergency/inpatient facilities. Those criteria were discussed and agreed upon by all services in the network, which improved communication between services.

\section{Improving continuity of care}

Continuity of care is the coordination and integration of different health care events to meet patient care needs in a coherent, connected, and consistent manner, ${ }^{92}$ and it is affected by the lack of consistent information exchanged between services in different care levels. The implementation of electronic health records, coupled with the transition of care software, can play a major role in proper case management in mental health teams. One example of this strategy was provided by the XIII Regional Health Department in São Paulo. ${ }^{93}$ Authors proposed an eHealth solution to fill the gap in the availability and quality of information within a network of health services to improve the continuity of care and health services management. A similar example was implemented in Porto Alegre. ${ }^{94}$ Figure 2 depicts how the systems are integrated. When primary care workers feel that a patient needs specialized care, they answer a series of questions in a software program to obtain a referral. Their requests are seen by a 


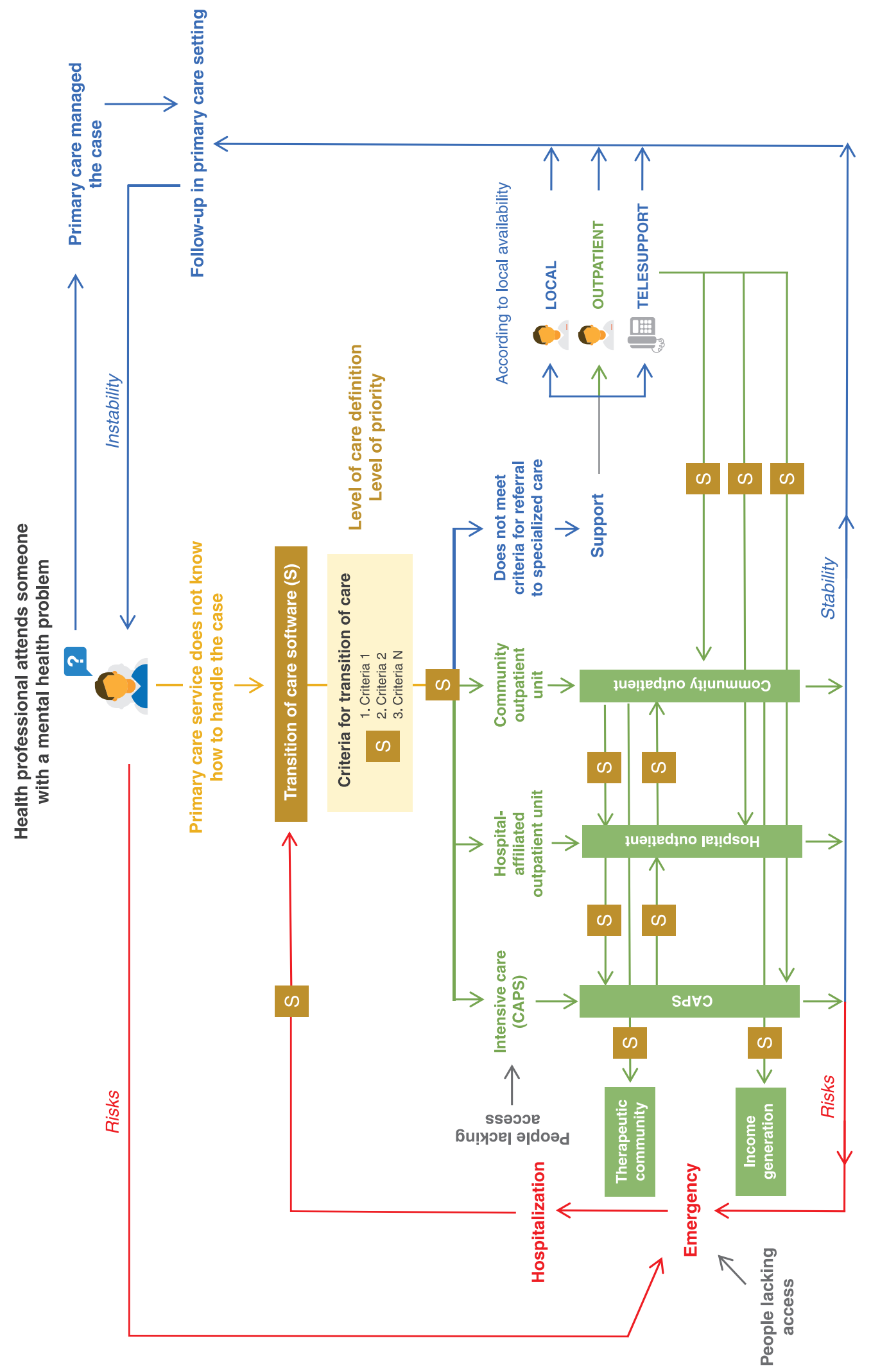

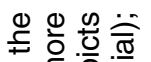

os

웅용

क्.

这船

o.

के क्षे

$\rightleftharpoons$ काष

号

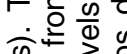

कo

व.

क

西 $\frac{\pi}{=} \cdot \frac{\pi}{0}$

o.

○ ऽ फ

Ф

엉 응

은융ㅇㅇ

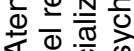

๑ 쥬

응 을

잉 Ф

ฯ

ญ 등 잉

ช $\varepsilon$

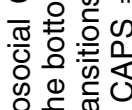

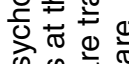

की

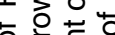

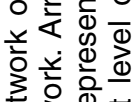

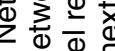

Ф) 옹

.

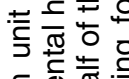

등 웓

ฮั ส 응

흐.

(1)

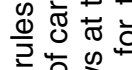

능

๑ั่ $\frac{\omega}{0}$ 은

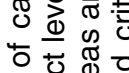

○ 웡

은 㐘 $\frac{\Phi}{3} \overline{0}$

ธิธ 워

징 Ð

ฮั

๘

듬 융허 헝

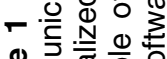

는 틍 으 잉

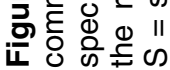




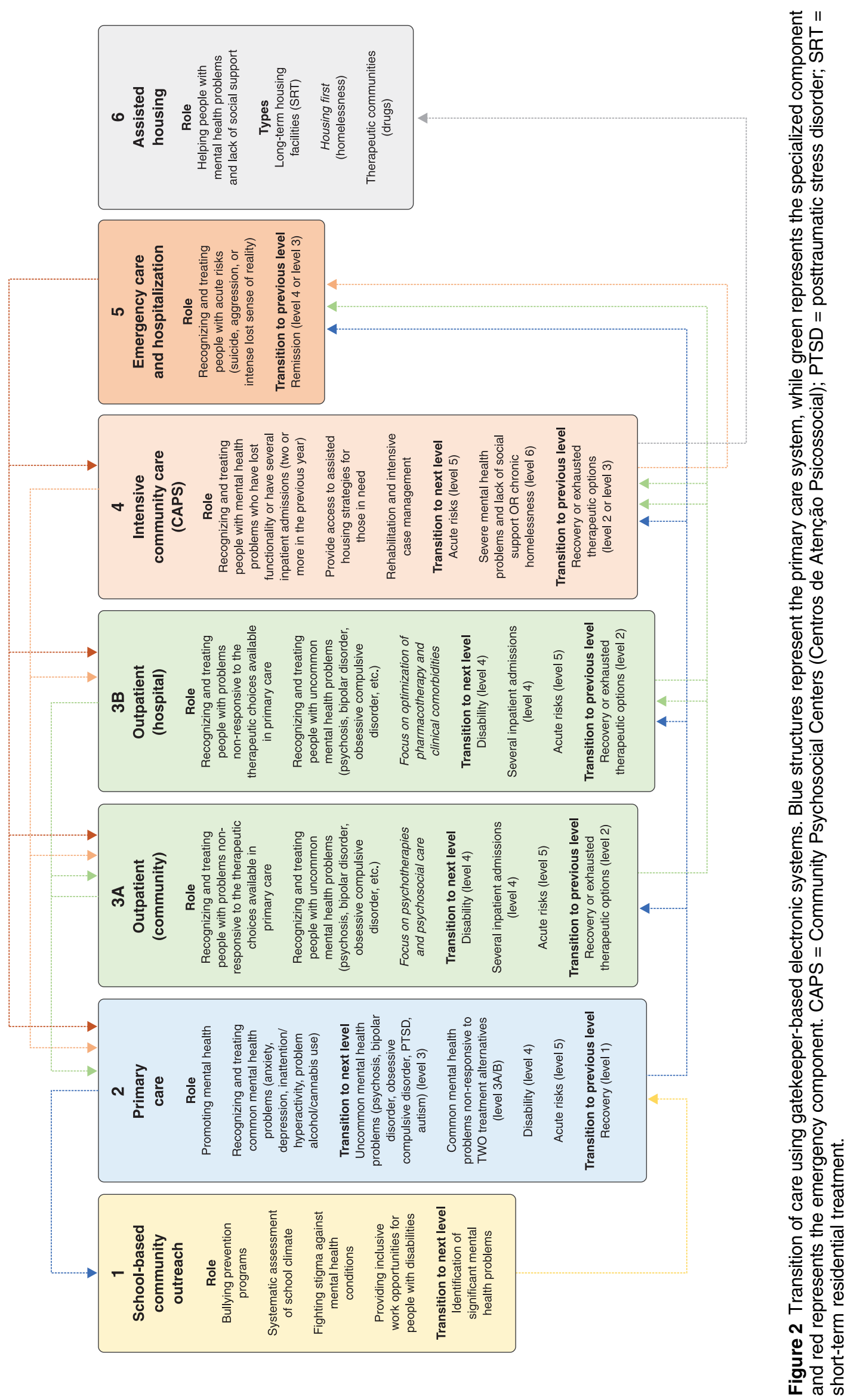


specialized psychiatry unit that remotely assesses the cases based on the matrix of mental conditions described above and decides whether to call the primary care physician to provide remote assistance (if it does not meet their criteria) or refer the case to the appropriate specialized care service (e.g., community-based outpatient center, hospital-based outpatient center, intensive care facility, emergency/inpatient facilities). This system involves an electronic method for providing health equity, which means that those with more severe mental health problems are prioritized.

\section{Conclusions and recommendations}

The COVID-19 pandemic may become the most striking natural psychological experiment that humanity has ever experienced on a global scale. ${ }^{95}$ The educational and socioemotional impacts of prolonged absence from school on children and adolescents have yet to be measured, especially for those most socially vulnerable and those with existing mental disorders. Considering the limited access to mental health systems that already preceded the pandemic in Brazil, action is needed to allow vulnerable individuals and families to receive adequate care. Some actions can be readily taken, such as active engagement of youth in the conceptual stages of research design and interventions, where they can support each other.

Once adolescents return to school, educational authorities should catalyze the incorporation of adapted and evaluated prevention programs to reduce violence, bullying, and misconduct and programs aiming to develop general social skills as a means of reducing alcohol and drug use in primary and secondary schools.

Regarding severe mental illness, an increase in morbidity and mortality is expected as a direct result of the pandemic, as are increasing relapse and incidence rates of psychotic disorders. This will be compounded by the fact that the pandemic has led most primary and secondary mental health facilities to either close or temporarily restrict appointments. Expanding specialized care to first-episode patients is recommended as a costeffective strategy, alongside investing in technology developments to promote coordinated care. It is vital that the primary care system incorporate care delivery lines for tracking prescriptions and patients' physical and mental health needs, improving coverage and reducing risk of relapse. As an unintended positive consequence, quarantine measures certainly sped up the adoption of online solutions. For example, telemedicine was not allowed by the Brazilian Federal Medical Council before the pandemic, but now, it is at the heart of a mental health care revolution: reducing costs, promoting coordinated care, adhering to professional guidelines, and allowing easier access by patients. Overall, the literature suggests that mobile apps and telehealth assistance is feasible, costeffective, engaging, and well-accepted. ${ }^{96}$ In Brazil and other LMICs, mental health systems are not familiar with caring for psychotic patients through mobile apps, web-based algorithms, or telehealth support. Thus, technological development needs more funding, which can be achieved more efficiently through public-private partnerships.
The change in Brazil's demographic profile will place those at age 60 and older at higher risk from physical and mental problems such as dementia, depression, and suicide because of quarantine and other social isolation measures. Since a high proportion of older Brazilians have limited access to information and communications technologies such as mobile phones and computers, it is important to expand internet access to older people to facilitate social networking, integration, and maintenance of connectivity after the pandemic. Primary care teams can also provide long-term support and assertive care in older adults' homes to manage common mental health problems.

Some populations are living in extremely precarious confinement conditions, with limited access to resources and denial of basic rights even before the pandemic; it is essential that their vulnerable status be recognized. Black Brazilians, for example, represent over $52 \%$ of the general population, but are disproportionately represented among the homeless, imprisoned, and extremely impoverished. This population demands special attention both for the specific comorbidities that affects it (e.g., hypertension, diabetes, and sickle cell anemia) and for the social lethality it suffers because of historically entrenched and politically motivated structural racism and violence.

The main limitation of this paper is that the recommendations presented herein were not based on a standardized literature review. However, the experts utilized are leading scientists in their field and were asked to select the best scientific evidence available. The recommendations provided are clear, feasible, and should be readily adopted by Brazilian policymakers, which is the main aim of this task force. Furthermore, most of these proposals can be applied in similar LMIC countries.

Despite considerable advances, major gaps remain for Brazilian RAPs and similar networks in other LMICs. An important problem faced by the mental health system is the low level of care coordination. A proposal for roles and clear care transition criteria for each level of care is displayed in the RAPs. Creating a "matrix of mental health conditions and services" can help fill the gap in the availability and quality of information within a health services network and could potentially improve the continuity of care and health services management. Moreover, it is paramount to develop telehealth interventions that are directed at common mental disorders and expand strategies such as brief psychotherapy and telemedicine, always taking advantage of and fostering the primary health care strategy that is a cornerstone of the Brazilian Unified Health System.

\section{Acknowledgements}

JJM is a Conselho Nacional de Desenvolvimento Científico e Tecnológico (CNPq) senior research fellow. JJM and ZMS are recipients of a Research and Innovation grant for the Prevention of Mental Disorders and Use of Alcohol and other Drugs (Pesquisas e Inovações em Prevenção de Transtornos Mentais e Uso de Álcool e Outras Drogas), funded by the Brazilian Ministry of Health 
(TED \#176/2017). JJM, AG, and GAS are supported by Instituto Nacional de Psiquiatria do Desenvolvimento para Crianças e Adolescentes (INPD) (grants: CNPq 465550/ 2014-2 and Fundação de Amparo à Pesquisa do Estado de São Paulo [FAPESP] 2014/50917-0). AEN has received financial support for this research from $\mathrm{CNPq}$ and Fundação de Amparo à Pesquisa do Estado do Rio de Janeiro (FAPERJ). CK is a CNPq researcher and a UK Academy of Medical Sciences Newton Advanced Fellow. NA-F is a CNPq senior research fellow (award no. 304671/2016-9) and PI of the Instituto Nacional de Ciência e Tecnologia de Inclusão no Ensino e na Pesquisa (INCTI) program on Innovation, Technology and Equity in Health (Inovação, Tecnologia e Equidade em Saúde - INTEQSaude), funded by the CNPq (proc. 441670/2018-0). GAS is a CNPq research fellow and receives support from the Brazilian Ministry of Health (TED 16/2020 and TED 140/ 2019).

The authors thank Professor Helena Nader for her important suggestions.

\section{Disclosure}

The authors report no conflicts of interest.

\section{References}

1 Demenech LM, Dumith SC, Vieira ME, Neiva-Silva L. Income inequality and risk of infection and death by COVID-19 in Brazil. Rev Bras Epidemiol. 2020;23:e200095.

2 Samaja JA. Epistemología y metodología: elementos para una teoria de la investigación científica. Buenos Aires: Editorial Universitaria de Buenos Aires; 2004.

3 Almeida filho N. Modelagem da pandemia Covid-19 como objeto complexo (notas samajianas). Estud Av. 2020;34:97-118.

4 Wang G, Zhang Y, Zhao J, Zhang J, Jiang F. Mitigate the effects of home confinement on children during the COVID-19 outbreak. Lancet. 2020;395:945-7.

5 Horton R. Offline: COVID-19 is not a pandemic. Lancet. 2020;396: 935.

6 Twenge JM, Joiner TE. U.S. Census Bureau-assessed prevalence of anxiety and depressive symptoms in 2019 and during the 2020 COVID-19 pandemic. Depress Anxiety. 2020;37:954-6.

7 McGinty EE, Presskreischer R, Han H, Barry CL. Psychological distress and loneliness reported by US adults in 2018 and April 2020. JAMA. 2020;324:93-4.

8 De Boni RB, Balanza-Martinez V, Mota JC, Cardoso TA, Ballester P, Atienza-Carbonell B, et al. Depression, anxiety and lifestyle among essential workers: a websurvey from Brazil and Spain during the Covid-19 pandemic. J Med Internet Res. 2020;22:e22835.

9 Carta MG, Nardi AE, Bhugra D. New technologies for social inclusion of people with psychosocial disabilities in the era of COVID-19 and beyond. Braz J Psychiatry. 2021;43:231-2.

10 Salum GA, Rehmenklau JF, Csordas MC, Pereira FP, Castan JU, Ferreira $A B$, et al. Supporting people with severe mental health conditions during the COVID-19 pandemic: considerations for lowand middle-income countries using telehealth case management. Braz J Psychiatry. 2020;42:451-2.

11 Fegert JM, Vitiello B, Plener PL, Clemens V. Challenges and burden of the Coronavirus 2019 (COVID-19) pandemic for child and adolescent mental health: a narrative review to highlight clinical and research needs in the acute phase and the long return to normality. Child Adolesc Psychiatry Ment Health. 2020;14:20.

12 Danese A, Smith P, Chitsabesan P, Dubicka B. Child and adolescent mental health amidst emergencies and disasters. $\mathrm{Br} \mathrm{J}$ Psychiatry. 2020;216:159-62.

13 Jefsen $\mathrm{OH}$, Rohde $\mathrm{C}$, Norremark B, Ostergaard SD. Editorial perspective: COVID-19 pandemic-related psychopathology in children and adolescents with mental illness. J Child Psychol Psychiatry. 2020 Jul 7; doi: 10.1111/jcpp.13292. Online ahead of print.

14 Asbury K, Fox L, Deniz E, Code A, Toseeb U. How is COVID-19 affecting the mental health of children with special educational needs and disabilities and their families? J Autism Dev Disord. 2020 Jul 31;1-9. doi: 10.1007/s10803-020-04577-2. Online ahead of print.

15 Cluver L, Lachman JM, Sherr L, Wessels I, Krug E, Rakotomalala S, et al. Parenting in a time of COVID-19. Lancet. 2020;395:e64.

16 Pavarini G, Lyreskog D, Manku K, Musesengwa R, Singh I. Debate: promoting capabilities for young people's agency in the COVID-19 outbreak. Child Adolesc Ment Health. 2020;25:187-8.

17 Patton GC, Sawyer SM, Santelli JS, Ross DA, Afifi R, Allen NB, et al. Our future: a Lancet commission on adolescent health and wellbeing. Lancet. 2016;387:2423-78.

18 Instituto Brasileiro de Geografia e Estatística (IBGE). Pesquisa nacional de saúde do escolar 2015 [Internet]. Rio de Janeiro: IBGE; 2016 [cited 2020 Dec 20]. biblioteca.ibge.gov.br/visualizacao/livros/ liv97870.pdf

19 Mello FC, da Silva JL, de Oliveira WA, do Prado RR, Malta DC, lossi Silva MA. The practice of bullying among Brazilian schoolchildren and associated factors, National School Health Survey 2015. Cien Saude Colet. 2017;22:2939-48.

20 Horta CL, Horta RL, Mester A, Lindern D, Weber JL, Levandowski DC, et al. [Bullying and psychoactive substance use during adolescence: a systematic review]. Cien Saude Colet. 2018;23:123-40.

21 Cox E, Leung R, Baksheev G, Day A, Toumbourou JW, Miller P, et al. Violence prevention and intervention programmes for adolescents in australia: a systematic review. Aust Psychol. 2016;51:206-22.

22 Imran N, Aamer I, Sharif MI, Bodla ZH, Naveed S. Psychological burden of quarantine in children and adolescents: a rapid systematic review and proposed solutions. Pak J Med Sci. 2020;36:1106-16.

23 Strom HK, Adolfsen F, Fossum S, Kaiser S, Martinussen M. Effectiveness of school-based preventive interventions on adolescent alcohol use: a meta-analysis of randomized controlled trials. Subst Abuse Treat Prev Policy. 2014;9:48.

24 Faggiano F, Vigna-Taglianti FD, Versino E, Zambon A, Borraccino A, Lemma P. School-based prevention for illicit drugs' use. Cochrane Database Syst Rev. 2005(2):CD003020.

25 Jackson C, Geddes R, Haw S, Frank J. Interventions to prevent substance use and risky sexual behaviour in young people: a systematic review. Addiction. 2012;107:733-47.

26 Werch CE, Owen DM. latrogenic effects of alcohol and drug prevention programs. J Stud Alcohol. 2002;63:581-90.

27 Lee NK, Cameron J, Battams S, Roche A. What works in schoolbased alcohol education: a systematic review. Health Educ J. 2016;75:780-98.

28 Brasil, Ministério da Saúde. Prevenção ao uso de drogas: implantação e avaliação de programas no Brasil [Internet]. 2018 [cited 2020 Dec 19]. edisciplinas.usp.br/pluginfile.php/4958325/mod_resource/ content/1/prevencao_uso_drogas.pdf

29 Faggiano F, Vigna-Taglianti F, Burkhart G, Bohrn K, Cuomo L, Gregori D, et al. The effectiveness of a school-based substance abuse prevention program: 18-month follow-up of the EU-Dap cluster randomized controlled trial. Drug Alcohol Depend. 2010;108:56-64.

30 Kellam SG, Wang W, Mackenzie AC, Brown CH, Ompad DC, Or F, et al. The impact of the Good Behavior Game, a universal classroombased preventive intervention in first and second grades, on high-risk sexual behaviors and drug abuse and dependence disorders into young adulthood. Prev Sci. 2014;15 Suppl 1:S6-18.

31 Allen D, Coombes L, Foxcroft DR. Cultural accommodation of the Strengthening Families Programme 10-14: UK phase I study. Health Educ Res. 2007;22:547-60.

32 Sussman S, Earleywine M, Wills T, Cody C, Biglan T, Dent CW, et al. The motivation, skills, and decision-making model of "drug abuse" prevention. Subst Use Misuse. 2004;39:1971-2016.

33 Giannotta F, Vigna-Taglianti F, Galanti MR, Scatigna M, Faggiano F. Short-term mediating factors of a school-based intervention to prevent youth substance use in Europe. J Adolesc Health. 2014;54: 565-73.

34 Sanchez ZM, Valente JY, Sanudo A, Pereira AP, Cruz JI, Schneider $D$, et al. The \#Tamojunto drug prevention program in Brazilian Schools: a randomized controlled trial. Prev Sci. 2017;18:772-82.

35 Sanchez ZM, Sanudo A, Andreoni S, Schneider D, Pereira AP, Faggiano F. Efficacy evaluation of the school program Unplugged for 
drug use prevention among Brazilian adolescents. BMC Public Health. 2016;16:1206.

36 Gusmões JD, Sañudo A, Valente JY, Sanchez ZM. Violence in Brazilian schools: analysis of the effect of the \#Tamojunto prevention program for bullying and physical violence. J Adolesc. 2018;63:107-17.

37 Embry DD. The Good Behavior Game: a best practice candidate as a universal behavioral vaccine. Clin Child Fam Psychol Rev. 2002;5:273-97.

38 Joslyn PR, Donaldson JM, Austin JL, Vollmer TR. The Good Behavior Game: a brief review. J Appl Behav Anal. 2019;52:811-5.

39 Groves EA, Austin JL. Does the Good Behavior Game evoke negative peer pressure? Analyses in primary and secondary classrooms. J Appl Behav Anal. 2019;52:3-16.

40 Foxcroft DR, Ireland D, Lister-Sharp DJ, Lowe G, Breen R. Longerterm primary prevention for alcohol misuse in young people: a systematic review. Addiction. 2003;98:397-411.

41 Kumpfer KL, Whiteside HO, Greene JA, Allen KC. Effectiveness outcomes of four age versions of the Strengthening Families Program in statewide field sites. Group Dyn. 2010;14:211-29.

42 Schneider DR, Pereira AP, Cruz JI, Strelow M, Chan G, Kurki A, et al. Evaluation of the implementation of a preventive program for children in Brazilian schools. Psicol Cienc Prof. 2016;36:508-19.

43 Pedroso RT, Hamann EM. Adaptations of the pilot of the Unplugged \#tamojunto program for health promotion and drug prevention in Brazilian schools. Cienc Saude Colet. 2019;24:371-81.

44 Murta SG, Nobre-Sandoval LdA, Pedralho MdS, Tavares TN, Ramos $\mathrm{CE}$, Allen D, et al. Needs assessment for cultural adaptation of Strengthening Families Program (SFP 10-14-UK) in Brazil. Psicol Reflex Crit. 2018;31:25.

45 Medeiros PF, Cruz JI, Schneider DR, Sanudo A, Sanchez ZM. Process evaluation of the implementation of the Unplugged Program for drug use prevention in Brazilian schools. Subst Abuse Treat Prev Policy. 2016;11:2.

46 Charlson FJ, Ferrari AJ, Santomauro DF, Diminic S, Stockings E, Scott JG, et al. Global epidemiology and burden of schizophrenia: findings from the global burden of disease study 2016. Schizophr Bull. 2018;44:1195-203.

47 Jaaskelainen E, Juola P, Hirvonen N, McGrath JJ, Saha S, Isohanni $\mathrm{M}$, et al. A systematic review and meta-analysis of recovery in schizophrenia. Schizophr Bull. 2013;39:1296-306.

48 Saha S, Chant D, McGrath J. A systematic review of mortality in schizophrenia: is the differential mortality gap worsening over time? Arch Gen Psychiatry. 2007;64:1123-31.

49 Magliano L, Fiorillo A, De Rosa C, Malangone C, Maj MNational Mental Health Project Working G. Family burden in long-term diseases: a comparative study in schizophrenia vs. physical disorders. Soc Sci Med. 2005;61:313-22.

50 Brasil, Ministério da Saúde. Protocolo clínico e diretrizes terapêuticas: esquizofrenia [Internet]. 2014 [cited 2020 dec 18]. portalarquivos.saude.gov.br/images/pdf/2014/abril/02/pcdt-esquizofrenialivro-2013.pdf

51 Fonseca L, Diniz E, Mendonca G, Malinowski F, Mari J, Gadelha A. Schizophrenia and COVID-19: risks and recommendations. Braz Psychiatry. 2020;42:236-8.

52 Brown E, Gray R, Lo Monaco S, O'Donoghue B, Nelson B, Thompson A, et al. The potential impact of COVID-19 on psychosis: a rapid review of contemporary epidemic and pandemic research. Schizophr Res. 2020;222:79-87.

53 Finatti F, Pigato G, Pavan C, Toffanin T, Favaro A. Psychosis in patients in COVID-19-related quarantine: a case series. Prim Care Companion CNS Disord. 2020;22:20102640.

54 Csillag C, Nordentoft M, Mizuno M, Jones PB, Killackey E, Taylor M, et al. Early intervention services in psychosis: from evidence to wide implementation. Early Interv Psychiatry. 2016;10:540-6.

55 Correll CU, Galling B, Pawar A, Krivko A, Bonetto C, Ruggeri M, et al. Comparison of early intervention services vs treatment as usual for early-phase psychosis: a systematic review, meta-analysis, and meta-regression. JAMA Psychiatry. 2018;75:555-65.

56 Aceituno D, Vera N, Prina AM, McCrone P. Cost-effectiveness of early intervention in psychosis: systematic review. $\mathrm{Br} \mathrm{J}$ Psychiatry. 2019;215:388-94.

57 Saxena S, Thornicroft G, Knapp M, Whiteford H. Resources for mental health: scarcity, inequity, and inefficiency. Lancet. 2007;370: 878-89.
58 Bhugra D, Tasman A, Pathare S, Priebe S, Smith S, Torous J, et al. The WPA Lancet Psychiatry Commission on the future of psychiatry. Lancet Psychiatry. 2017;4:775-818.

59 Instituto Brasileiro de Geografia e Estatística (IBGE). Projeções e estimativas da população do Brasil e das Unidades da Federação [Internet]. [cited 2020 Oct 17]. www.ibge.gov.br/apps/populacao/ projecao/

60 Steptoe A, Shankar A, Demakakos P, Wardle J. Social isolation, loneliness, and all-cause mortality in older men and women. Proc Natl Acad Sci U S A. 2013;110:5797-801.

61 Gyasi RM, Yeboah AA, Mensah CM, Ouedraogo R, Addae EA Neighborhood, social isolation and mental health outcome among older people in Ghana. J Affect Disord. 2019;259:154-63.

62 World Health Organization (WHO). Mental health of older adults 2017 [Internet]. 2017 Dec 12 [cited 2018 Aug 16]. www.who.int/news-room/ fact-sheets/detail/mental-health-of-older-adults

63 Gullich I, Duro SM, Cesar JA. Depression among the elderly: a population-based study in Southern Brazil. Rev Bras Epidemiol. 2016;19:691-701.

64 Brasil, Ministério da Saúde. Taxa de suicídio é maior em idosos com mais de 70 anos [Internet]. 2017 [cited 2020 Dec 18]. www.gov.br/ saude/pt-br/assuntos/noticias/taxa-de-suicidio-e-maior-em-idosos-com mais-de-70-anos

65 SEADE, Fundação Sistema Estadual de Analise de dados. SP contra o novo coronavírus [Internet]. 2020 Aug 16 [cited 2020 Dec 18]. www. seade.gov.br/coronavirus/

66 Wachholz PA, Moreira VG, Oliveira D, Watanabe HA, Villas Boas PJ. Occurrence of infection and mortality by COVID-19 in care homes for older people in Brazil. SCIELO Preprints. 2020 Aug 3; doi: https://doi. org/10.1590/SciELOPreprints.1032. Online ahead of print.

67 Luo Y, Hawkley LC, Waite LJ, Cacioppo JT. Loneliness, health, and mortality in old age: a national longitudinal study. Soc Sci Med. 2012;74:907-14.

68 Courtin E, Knapp M. Social isolation, loneliness and health in old age: a scoping review. Health Soc Care Community. 2017;25: 799-812.

69 Wand AP, Zhong BL, Chiu HF, Draper B, De Leo D. COVID-19: the implications for suicide in older adults. Int Psychogeriatr. 2020;32: 1225-30.

70 Esain I, Gil SM, Bidaurrazaga-Letona I, Rodriguez-Larrad A. Effects of 3 months of detraining on functional fitness and quality of life in older adults who regularly exercise. Aging Clin Exp Res. 2019;31: 503-10.

71 Sociedade Brasileira de Geriatria e Gerontologia. Em Dia Mundial do Alzheimer, dados ainda são subestimados, apesar de avanços no diagnóstico e tratamento da doença [Internet]. 2019 [CITED 2020 Aug 16]. sbgg.org.br/em-dia-mundial-do-alzheimer-dadosainda-sao-subestimados-apesar-de-avancos-no-diagnostico-e-trat amento-da-doenca/

72 Rehm J, Kilian C, Ferreira-Borges C, Jernigan D, Monteiro M, Parry $\mathrm{CD}$, et al. Alcohol use in times of the COVID 19: implications for monitoring and policy. Drug Alcohol Rev. 2020;39:301-4.

73 Rollston R, Galea S. COVID-19 and the social determinants of health Am J Health Promot. 2020;34:687-9.

74 Tai DB, Shah A, Doubeni CA, Sia IG, Wieland ML. The disproportionate impact of COVID-19 on racial and ethnic minorities in the United States. Clin Infect Dis. 2020 Jun 20;ciaa815. doi: 10.1093/cid/ ciaa815. Online ahead of print.

75 Wadhera RK, Wadhera P, Gaba P, Figueroa JF, Joynt Maddox KE, Yeh RW, et al. Variation in COVID-19 hospitalizations and deaths across New York City boroughs. JAMA. 2020;323:2192-5.

76 Burstrom B, Tao W. Social determinants of health and inequalities in COVID-19. Eur J Public Health. 2020;30:617-8.

77 de Souza CD, Machado MF, do Carmo RF. Human development social vulnerability and COVID-19 in Brazil: a study of the social determinants of health. Infect Dis Poverty. 2020;9:124.

78 Komatsu BK, Menezes-Filho N. Simulações de impactos da COVID19 e da renda básica emergencial sobre o desemprego, renda, pobreza e desigualdade [Internet]. 202 Policy Paper, $N^{\circ}$ 43. $2020 \mathrm{Apr}$ [cited 2020 dec 18]. www.insper.edu.br/wp-content/uploads/2020/04/ Policy-Paper-v14.pdf

79 De Melo CM, Silva GA, Melo AR, De Freitas AC. COVID-19 pandemic outbreak: the Brazilian reality from the first case to the collapse of health services. An Acad Bras Cienc. 2020;92:e20200709. 
80 Organização Mundial de Saúde (OMS). Declaração de Caracas 1990 [Internet]. 1990 Nov 14 [cited 2020 dec 18]. laps.ensp.fiocruz. br/arquivos/documentos/12

81 Brasil, Casa Civil. Lei $n^{\circ} 10.216$, de 6 de abril de 2001. Dispõe sobre a proteção e os direitos das pessoas portadoras de transtornos mentais e redireciona o modelo assistencial em saúde mental; 2001. www.planalto.gov.br/ccivil_03/leis/leis_2001/l10216.htm

82 Brasil, Ministério da Saúde. Portaria N ${ }^{\circ} 336$, DE 19 de fevereiro de 2002. bvsms.saude.gov.br/bvs/saudelegis/gm/2002/prt0336_19_02_ 2002.html

83 Brasil, Ministério da Saúde. Portaria $n^{\circ} 3.088$, de 23 de dezembro de 2011(*) - Institui a Rede de Atenção Psicossocial para pessoas com sofrimento ou transtorno mental e com necessidades decorrentes do uso de crack, álcool e outras drogas, no âmbito do Sistema Único de Saúde (SUS). bvsms.saude.gov.br/bvs/saudelegis/gm/2011/prt3088_ 23_12_2011_rep.html

84 Brasil, Ministério da Saúde. Portaria $n^{\circ} 3.588$, de 21 de dezembro de 2017. Altera as Portarias de Consolidação $n^{\circ} 3$ e $n^{\circ} 6$, de 28 de setembro de 2017, para dispor sobre a Rede de Atenção Psicossocial, e dá outras providências. bvsms.saude.gov.br/bvs/ saudelegis/gm/2017/prt3588_22_12_2017.html

85 Lopes CS, Hellwig N, de Azevedo e Silva G, Menezes PR. Inequities in access to depression treatment: results of the Brazilian National Health Survey - PNS. Int J Equity Health. 2016;15:154.

86 Quintana MI, Andreoli SB, Peluffo MP, Ribeiro WS, Feijo MM, Bressan RA, et al. Psychotropic drug use in Sao Paulo, Brazil--an epidemiological survey. PLoS One. 2015;10:e0135059.

87 Quintana MI, Andreoli SB, Moreira FG, Ribeiro WS, Feijo MM, Bressan RA, et al. Epidemiology of psychotropic drug use in Rio de Janeiro, Brazil: gaps in mental illness treatments. PLoS One. 2013;8: e62270.

88 Menezes P, Quayle J, Claro HG, da Silva S, Brandt LR, DiezCanseco $\mathrm{F}$, et al. Use of a mobile phone app to treat depression comorbid with hypertension or diabetes: a pilot study in Brazil and Peru. JMIR Ment Health. 2019;6:e11698.

89 Ministério da Saúde, Hospital de Clínicas de Porto Alegre. TelePSI [Internet]. 2020 [cited 2020 Dec 18]. sites.google.com/hcpa.edu.br/ telepsi/

90 McDonald KM, Sundaram V, Bravata DM, Lewis R, Lin N, Kraft SA, et al. Definitions of care coordination and related terms. 2007. In: McDonald KM, Sundaram V, Bravata DM. Closing the quality gap: a critical analysis of quality improvement strategies. Rockville: Agency for Healthcare Research and Quality; 2007. v.7, Care Coordination.

91 Prefeitura de Porto Alegre, Biblioteca Virtual da Atenção Primária à Saúde (BVAPS). Saúde mental: profissional - material de apoio [Internet]. [cited $2020 \mathrm{dec}$ 18]. sites.google.com/view/bvsapspoa/ especialidades/sa\%C3\%BAde-mental?authuser $=0$

92 Haggerty JL, Reid RJ, Freeman GK, Starfield BH, Adair CE, McKendry R. Continuity of care: a multidisciplinary review. BMJ. 2003;327:1219-21.

93 Miyoshi NS, De Azevedo-Marques JM, Alves D, De AzevedoMarques PM. An eHealth platform for the support of a Brazilian Regional Network of Mental Health Care (eHealth-Interop): development of an interoperability platform for mental care integration. JMIR Ment Health. 2018;5:e10129.

94 Prefeitura de Porto Alegre, Gerenciamento de consultas (Gercon). Sistema de regulação de consultas especializadas do SUS para a Secretaria Municipal da Saúde de Porto Alegre [Internet]. [cited 2020 Dec 18]. gercon.procempa.com.br/gerconweb/\#/

95 Mari JJ, Oquendo MA. Mental health consequences of COVID-19: the next global pandemic. Trends Psychiatry Psychother. 2020;42: 219-20.

96 Alvarez-Jimenez M, Alcazar-Corcoles MA, Gonzalez-Blanch C, Bendall S, McGorry PD, Gleeson JF. Online, social media and mobile technologies for psychosis treatment: a systematic review on novel user-led interventions. Schizophr Res. 2014;156:96-106. 